\title{
A reforma do Estado e a gestão democrática na universidade pública brasileira
}

\section{State reform and democratic management in Brazilian public university}

\author{
Eliana Vieira Turíbio \\ Mestrado em Gestão Social, Educação e Desenvolvimento Local / Centro Universitário UNA \\ Assistente Social / Universidade Federal de Minas Gerais \\ http://lattes.cnpq.br/4646124387121203 \\ https://orcid.org/0000-0001-6283-0585 \\ vieiraturibio@yahoo.com.br \\ Eloisa Helena Santos \\ Doutorado em Ciências da Educação / Universidade de Paris VIII (França) \\ Professora / Centro Universitário UNA \\ http://lattes.cnpq.br/8399335352215787 \\ https://orcid.org/0000-0001-6986-5502 \\ eloisasantos@uaivip.com.b
}

Resumo: Este artigo aborda a reforma do Estado implementada na década de 1990, no Brasil, e seus impactos sobre as universidades públicas que necessitaram se adaptar à nova política de diversificação e diferenciação, que mensura seu valor pela competitividade e capacidade de inovação. Destaca a perda de controle sobre a definição de sua identidade, funções e gestão. A autonomia universitária e a democratização da gestão são apontadas como fundamentais na resistência ao gerencialismo. A participação social comparece como elemento primordial na gestão democrática da educação. $O$ artigo realça que movimentos sociais, dentro e fora das universidades, buscam a efetiva partilha de poder nas instâncias decisórias. Embora chame a atenção para o fato de que universidades mantêm uma gestão centralizada e vertical que resiste às ideias e opiniões forjadas nos novos espaços participativos, o artigo acena com uma reforma criativa, democrática e emancipatória da universidade pública como alternativa para enfrentamento das pressões neoliberais.

Palavras-chave: Neoliberalismo. Universidade Pública. Gestão Democrática. Participação Social.

Abstract: This article approaches the reform of the State implemented in 1990s, in Brazil, and its impacts on public universities, which needed to adapt to the new diversification and differentiation policy that measures their value by competitiveness and innovativeness. It gives prominence to the loss of control over the definition of its their identify, functions and management. University autonomy and management democratization identified as essential at to the resistance to managerialism. Social participation appears as a primordial element in democratic management of education. The article highlights that social movements, inside and outside universities, seek an effective sharing of power in the decision-making process. Although it attracts attention to the fact that universities keep a centralized and vertical management system that resist to suggestions and opinions forged in the new participatory spaces, the article mentions an emancipatory, democratic and creative reform of public university as alternative to confronting the neoliberal pressures.

Keywords: Neoliberalism. Public university. Democratic management. Social participation.

Texto completo em português: http://www.apgs.ufv.br Full text in Portuguese: http://www.apgs.ufv.br

\section{Introdução}

Este texto trata de dois temas que se entrelaçam na conformação de um olhar sobre a política de educação no Brasil, especialmente no nível superior de ensino. Situa-se a partir da década de 1990, quando novas determinações legais e de cunho econômico mudaram seus contornos e, por que não dizer, sua essência.

Inicialmente, explicita-se o tema da gestão democrática na educação pública superior brasileira de maneira a esclarecer em que medida a hegemonia neoliberal influenciou a intervenção do Estado nesta área. Além disto, destaca-se o caráter dúbio do controle e regulação sobre esta política: a proposta de aplicação da lógica gerencial e, contraditoriamente, de democratização da gestão nas instituições de ensino.

A segunda parte discorre sobre a participação social em espaços e processos de discussão, formulação e implementação de políticas públicas como uma importante contribuição dos cidadãos e, ao mesmo tempo, motivo de constantes embates pelos espaços e formas de sua realização. Apresenta-se, brevemente, o contexto sócio-histórico em que a sociedade se organiza para requerer o seu direito de influir nas políticas públicas que seriam implementadas no Brasil; como tem sido esta participação nas universidades públicas; e ainda uma proposta de reforma universitária para enfrentar os limites à efetivação de sua autonomia, impostos pelo neoliberalismo.

\section{A gestão democrática na educação pública superior no Brasil}

A gestão democrática da educação pública, como princípio da política pública de educação brasileira, é um dos frutos da luta dos movimentos sociais pela educação em nosso país. Ela foi determinada na Constituição do Brasil (1988) em seu Art. 206, inciso VI, regulamentada na Lei de Diretrizes e Bases da Educação Nacional de 1996 (LDBEN/1996) em seu Art. 3으, inciso VIII, e ratificada no Plano Nacional de Educação (PNE) 2014-2024. Tratase de um tema muito discutido nas últimas décadas por ter sido percebido por diversos autores como um campo de disputa entre os interesses públicos e privados/mercantis, até mesmo no âmbito estatal. 
O termo democratização da educação a ser utilizado neste texto se refere ao que Mendonça (2001) denomina direito ao ensino de qualidade e à participação democrática na gestão das unidades escolares e dos sistemas de ensino. A democratização da educação corresponde, assim, à gestão democrática da educação, que também é nomeada por diferentes autores como gestão democrática da escola, gestão colegiada ou gestão participativa. Ela envolve a gestão da política educacional e a gestão de escolas/instituições escolares.

No que tange à gestão da política educacional, foi estabelecida no artigo 214 da Constituição do Brasil (1988) a necessidade de elaboração de um PNE. Seus objetivos são articular o sistema nacional de educação e definir diretrizes, objetivos, metas e estratégias de implementação para assegurar a manutenção e desenvolvimento do ensino em seus diversos níveis, etapas e modalidades. Entre as instâncias responsáveis pelo monitoramento de sua execução e do cumprimento de suas metas estão o Ministério da Educação (MEC), a Comissão de Educação da Câmara dos Deputados e a Comissão de Educação, Cultura e Esporte do Senado Federal, o Conselho Nacional de Educação (CNE) e o Fórum Nacional de Educação (FNE). Nascido das lutas sociais, este último é o responsável por coordenar a Conferência Nacional de Educação (CONAE), o espaço democrático de articulação entre o Poder Público e a sociedade para o desenvolvimento da Educação Nacional. A CONAE possuiu caráter deliberativo e apresenta um conjunto de propostas que subsidiam a implementação do PNE. Ela indica responsabilidades, corresponsabilidades, atribuições concorrentes, complementares e colaborativas entre os entes federados e os sistemas de ensino. Essa conferência ocorre a cada quatro anos e sua primeira edição deu-se em abril de 2010. É precedida de etapas preparatórias (conferências livres e conferências ordinárias municipais e/ou intermunicipais, estaduais e do Distrito Federal) a fim de garantir a participação de profissionais da educação, gestores educacionais, estudantes, pais, entidades sindicais, científicas, movimentos sociais e conselhos de educação, entre outros, nas discussões pertinentes à melhoria da educação nacional.

A gestão de escolas/instituições escolares da educação básica prevê a participação de profissionais da educação na elaboração do projeto pedagógico da escola e a participação das comunidades escolar e local nos conselhos escolares e equivalentes. Já nas instituições públicas de educação superior é assegurada a existência de órgãos colegiados deliberativos, dos quais devem participar os segmentos da comunidade institucional, local e regional.

Diante destes direcionamentos para as instituições escolares, quais seriam as condições encontradas no sistema público de ensino brasileiro, principalmente no nível superior, para que esta gestão democrática se concretize e, ainda, quais seriam os determinantes de tal situação?

Para responder a esta questão, busca-se apoio em autores que analisaram a interferência do mercado ou esfera privada/mercantil na relação entre Estado e sociedade, no que diz respeito ao campo da implementação de políticas públicas no país.

Barroso afirma que, a partir dos anos de 1980 , as políticas neoliberais cunhadas na Inglaterra e nos Estados Unidos preconizavam a "redução do papel do Estado e a criação de mercados, ou quase-mercados, nos setores tradicionalmente públicos - saúde, educação, transportes etc." (Barroso, 2005, p. 741 ), afetando muitos outros países que tomaram tais princípios econômicos como referenciais de desenvolvimento.

$\mathrm{O}$ autor destaca que a área da educação foi influenciada pelas ideias neoliberais que promoveram reformas estruturais com a redução da intervenção do Estado na provisão e na administração do serviço educativo. Sob estas orientações, o Estado passa a estimular a criação de mercados (de educação e de emprego) por meio do financiamento da educação e da privatização da propriedade e da gestão escolar. Com isto, percebe-se a transformação da ideia de "serviço público" em "serviços para clientes" e a substituição de "bem comum educativo" por "bens" diversos e desigualmente acessíveis. Consequentemente, os princípios fundadores da escola pública (a universalidade do acesso, a igualdade de oportunidades e a continuidade dos percursos escolares) não tiveram correspondência nas políticas, nas formas de organização, no currículo e nos métodos pedagógicos em que se assenta a escola de massas (Barroso, 2005).

Ideia semelhante é apresentada por Dourado (2007) que também afirma que, no campo das políticas educacionais, as modificações de ordem jurídico-institucional, em consonância com a reforma do Estado, resultaram em novos modelos de gestão na esfera pública. Introduziram-se as noções de eficiência, produtividade e racionalidade, inerentes à lógica capitalista, propostas pelos organismos multilateraisi, influenciando de forma incisiva a formulação de políticas educacionais brasileiras na década de 1990.

Esta relação público/privado e suas consequências para a gestão democrática da educação é analisada ainda por Peroni (2012), que indica um duplo movimento de mudanças que redefiniram o papel do Estado: por um lado, houve alteração da propriedade, ocorrendo a passagem do estatal para o público não estatal ou privado; por outro lado, permaneceu a propriedade estatal, mas passou a haver a lógica de mercado, reorganizando, principalmente, os processos de gestão, chamados de quasemercado por alguns autores. Para essa autora, a materialização destas mudanças teve início no Plano Diretor da Reforma do Estado, estabelecido em 1995, quando as políticas sociais passaram a ser consideradas serviços não exclusivos do Estado, podendo ser também de propriedade pública não estatal ou privada. Esta situação teve continuidade nos governos de anos posteriores, mas não significou, segundo a autora, a superação do patrimonialismo, do clientelismo e até da administração burocrática nas práticas vivenciadas pela escola.

Souza e Castro (2012), por sua vez, destacam que a aliança firmada entre o Estado e o mercado acaba por despolitizar os 
processos de autonomia e descentralização, dando primazia à visão instrumental e tecnocrática da educação.

Diante desse quadro, alguns autores se dedicaram mais detidamente ao estudo das condições existentes em instituições públicas de ensino, eivadas de características da gestão burocrática, gerencial e de quase-mercado, para a realização de processos de decisão baseados na participação e na deliberação pública.

Para Dourado (2007, 2011), a análise da gestão educacional implica seus processos de concepção e/ou de execução, bem como as relações sociais em que se forjam as condições para sua proposição e materialidade. Tal perspectiva, segundo o autor, implica identificar os tipos de regulação que incidem em tais processos. Com isto, pode-se compreender porque a gestão na área da educação comporta especificidades:

A escola, entendida como instituição social, tem sua lógica organizativa e suas finalidades demarcadas pelos fins políticopedagógicos que extrapolam o horizonte custo-benefício stricto sensu. Isto tem impacto direto no que se entende por planejamento e desenvolvimento da educação e da escola e, nessa perspectiva, implica aprofundamento sobre a natureza das instituições educativas e suas finalidades, bem como as prioridades institucionais, os processos de participação e decisão, em âmbito nacional, nos sistemas de ensino e nas escolas. (Dourado, 2007, p. 924).

No que diz respeito à educação superior no Brasil, Dourado (2011) confirma a articulação entre processos extra e intrainstitucionais que convergem para a materialização da ação do estado/governo. Tanto o processo educativo quanto as políticas educacionais "são mediados pelo contexto sociocultural mais amplo, bem como pelas regulamentações, regulações e dinâmicas de financiamento, que impactam os processos de organização e gestão da educação superior" (Dourado, 2010 como citado em Dourado, 2011, p. 54). O autor cita, como instrumentos de alterações significativas na educação superior no Brasil, a LDBEN/1996 e os vários dispositivos a ela incorporados, bem como as metas traçadas em cada PNE desde sua primeira versão, aprovada em 2001.

Oliveira e Catani (2011) também afirmam que as políticas implementadas "desde a segunda metade da década de 1990 implicaram em mudanças significativas no papel, nos valores e nas finalidades das instituições de ensino superior (IES), particularmente nas universidades públicas, e no campo científico, em geral" (Oliveira \& Catani, 2011, p.13). O que também foi percebido por Ferreira e Oliveira (2011) e por Maia (2011). Esta última remete-se a Dourado para exprimir uma apreciação sucinta, porém esclarecedora:

Essas políticas, sobretudo na era $\mathrm{FHC}$, resultaram em um intenso processo de massificação e privatização da educação superior no Brasil, marcado pela precarização e privatização da agenda científica, negligenciando o papel social nesse nível de ensino, como espaço de investigação, discussão e difusão de projetos e modelos de organização da vida social, tendo por norte a garantia dos direitos sociais. (Dourado, 2002 como citado em Maia, 2011, p. 90).

Segundo Ferreira e Oliveira (2011) a reforma do Estado promovida no governo de FHC (1995-2002) implicou em redução de recursos para as universidades públicas, redução da autonomia universitária, incentivo às parcerias entre as universidades e as empresas, implantação de sistema de avaliação, entre outros. No governo Lula (2003-2010), percebe-se elementos de continuidade ao governo anterior como parcerias com setor produtivo e venda de serviço, maior concorrência entre as IES, adoção de planejamento estratégico, centralidade dos sistemas de avaliação e regulação, entre outros. Embora se identifiquem elementos convergentes, estes dois governos enfrentaram a questão da expansão da educação superior de forma diferente: o primeiro optou por expandir o acesso por meio das IES privadas, fomentar a competitividade entre as instituições mediante processos de avaliação, suspender contratação de professores e funcionários e ainda diminuir significativamente o financiamento das instituições federais de ensino superior. O segundo optou por expandi-las; contratar professores e funcionários; criar novas universidades, o Programa de Apoio a Planos de Reestruturação e Expansão das Universidades Federais (Reuni), o Plano de Desenvolvimento da Educação (PDE); expandir a Rede Federal de Educação Profissional e Tecnológica e implementar políticas de ações afirmativas, além do Programa Universidades para Todos (ProUni). Mesmo assim, segundo Ferreira e Oliveira (2011), a política educacional do governo Lula não escapou de cumprir as sugestões dos organismos internacionais, inclusive "a adoção de gestão mais profissional, gerencial e estratégica para o atingimento de metas" (Ferreira \& Oliveira, 2011, pp. 55).

Compreender tais mudanças experimentadas pelas universidades públicas, no que diz respeito ao seu papel, valores e finalidades, remete, portanto, a uma análise do contexto político e econômico em que se projetou um modelo de democratização da educação superior brasileira, bem como das atuais condições de sua materialização.

Inicialmente, apresentam-se certas especificidades desta que representou, até a última década do século passado, no país, a hegemonia do nível superior de ensino: a universidade pública. Passa-se, posteriormente, às determinações políticas e econômicas para a área de educação superior com todas as implicações para a gestão interna de cada uma destas instituições.

Chauí (2003) define a universidade pública como uma ação social, isto é,

Uma prática social fundada no reconhecimento público de sua
legitimidade e de suas atribuições, num princípio de diferenciação,
que Ihe confere autonomia perante outras instituições sociais e
estruturada por ordenamentos, regras, normas e valores de
reconhecimento e legitimidade internos a ela. (Chauí, 2003, p. 5,
grifo da autora).

Para a autora, a universidade "exprime de maneira determinada a estrutura e o modo de funcionamento da sociedade como um todo" (Chauí, 2003, p. 5). Portanto, podem ser percebidos, em seu interior, opiniões, atitudes e projetos conflitantes que revelam as divisões e contradições encontradas na sociedade. Ela identifica nessas características a razão de a universidade poder relacionarse com o todo da sociedade e com o Estado de maneira conflituosa. Existem, externa e internamente, grupos de posições políticas e ideológicas divergentes que buscam interferir nos processos de 
concretização republicana da instituição universitária, bem como em suas possibilidades democráticas. A demonstração clara disto é que, nos últimos anos, a universidade pública não conseguiu sair ilesa da Reforma do Estado promovida por um governo de orientação neoliberal, sofrendo grandes mudanças estruturais (Chauí, 2003).

Barroso (2005), Sguissard (2005, 2008, 2013) e Ferreira e Oliveira (2011) levantam o debate acerca das influências sofridas pelas universidades públicas com o processo de globalização e acumulação flexível do capital nas últimas décadas do século $\mathrm{XX}$. Eles trataram dos desafios enfrentados pelas universidades públicas quanto a suas identidades, suas funções, sua autonomia e sua gestão diante da reconfiguração do papel do Estado, provocada pela relação público/privado no campo da educação, bem como de outras políticas públicas.

Sguissard (2008) claramente define o Estado moderno como o espaço em que se realiza a contradição público versus privado/mercantil. Para o autor, trata-se de "uma construção social, espaço de contradição entre os interesses públicos e privados ou privado/mercantis, funcionando sob o predomínio ora destes, ora daqueles" (Sguissard, 2008, p. 1011). Nesta perspectiva, tem-se um Estado "semipúblico" e "semiprivado", que atende aos interesses sociais mais amplos, mas que também se encontra sob a orientação técnico-burocrática e que visa também os interesses privados/mercantis. Isto significa que o Estado enfrenta, em seu próprio âmbito, obstáculos à realização de sua função de regulação e controle para a garantia da preservação da educação como direito e bem público, que forme profissionais/cidadãos de uma sociedade com justiça e igualdade sociais (Sguissard, 2008). Estes empecilhos se apresentam de acordo com certas características ou posições assumidas pelo Estado que se referem à predominância de uma natureza pública ou privada/mercantil; à assunção de uma concepção de educação superior como um direito e bem público ou como um serviço e bem privado/mercantil; e, ainda às formas de regulação e de controle que serão privilegiadas - aquela que vise à competição, à eficiência e eficácia típica do mercado ou ao interesse público do cidadão. Com isto, o autor revela que o próprio Estado contém em si os obstáculos à universalização e à democratização da educação superior e demonstra que até mesmo a educação oferecida em órgãos públicos possui características da esfera privada/mercantil.

Dourado, Catani e Oliveira (2004) argumentam que a reforma da educação superior no Brasil, iniciada em 1995, promoveu mudanças estruturais, particularmente das universidades públicas. Foram alterados aspectos fundamentais como a gestão universitária; o padrão de financiamento; a avaliação de instituições, cursos e professores; os parâmetros curriculares de formação profissional; a avaliação e a produtividade de programas de pósgraduação; o trabalho docente; o relacionamento da universidade com as empresas, entre outros.

Este processo repleto de tensões, resistências e adaptações (Dourado, Catani \& Oliveira, 2004) imprimiu na universidade pública características de organização social que a tornariam competitiva e capaz de atender aos padrões da nova "política de diversificação e diferenciação que associou três princípios fundamentais: flexibilidade, competitividade e avaliação" (Dourado, Catani \& Oliveira, 2004, pp. 91-92 - grifos dos autores).

Chauí (2003) denominou como universidade operacional esta visão organizacional da universidade pública que, por ser

Definida e estruturada por normas e padrões inteiramente alheios ao conhecimento e à formação intelectual, está pulverizada em micro-organizações que ocupam seus docentes e curvam seus estudantes a exigências exteriores ao trabalho intelectual(Chauí, 2003, p. 7).

Dourado, Catani e Oliveira (2004) também abordam esse processo de modelação organizacional que tornou as IES mais funcionais e pragmáticas. Este perfil é traçado pela necessidade de ajustamento, sobrevivência e desenvolvimento institucional diante dos constrangimentos do mercado e do Estado ao projeto de constituição de uma universidade autônoma. Na realidade, o que se constituiu foi uma autonomia contratualizada que nega o estatuto da autonomia universitária (Dourado, Catani \& Oliveira, 2004), obrigando as instituições a cumprirem determinadas metas estabelecidas em uma negociação com o governo, por meio de contratos de gestão.

Dourado (2011) sinalizou para as consequências da vinculação cada vez mais estreita das IES ao mercado: a proposição e a materialização das políticas no nível de ensino superior se darão em "um cenário diversificado e, por vezes, contraditório, mas hegemonicamente marcado pela segmentação e competição entre as instituições e por mudanças substantivas na performance e nos valores institucionais" (Dourado, 2011, p. 63).

O financiamento da educação superior é destacado por Amaral (2011) como um ponto sensível, uma vez que a dependência dos recursos financeiros impacta na liberdade acadêmica das instituições. Estas, quando necessitam complementar os recursos insuficientes do fundo público, passam a realizar atividades de prestações de serviços por meio da oferta de cursos, assessorias e consultorias remuneradas, enfrentando o controle e os obstáculos à sua autonomia e liberdade intelectual por parte do Estado e também do mercado. As instituições públicas passam a viver uma tensão entre o estatal e o mercado, apresentando crises de hegemonia, de legitimidade e institucional e sofrem, por isto, a imposição de uma gestão empresarial, como se fossem empresas privadas. Ainda, segundo esse autor, constata-se no interior das instituições públicas uma mercantilização de serviços acadêmicos de forma sistemática inevitável, pois "o seguimento das normas impostas pelo quase-mercado tende, a cada dia que passa, a ser encarado como natural por muitos, dentro e fora das instituições, como se não houvesse de fato alternativa possível'. (Amaral, 2011, p. 84, grifos do autor).

Ferreira e Oliveira (2011) também explicitam que essas novas relações tecidas entre o Estado, a sociedade e o mercado favorecem a propagação do discurso de crise das universidades, de certo modo estimulando-as a procurarem modificar suas finalidades acadêmicas e sociais, a fim de se adequarem aos parâmetros 
mercadológicos. Destacam o Processo de Bolonhaii como o marco de criação, no bloco europeu, deste novo desenho de regulação e de reforma da educação, o qual tem sido referência para as mudanças implementadas na área da educação superior também na América Latina e em outros continentes.

Esses mesmos autores consideram que quando o valor destas instituições se mede pela competitividade, pela capacidade de inovação e de adaptação aos ditames neoliberais, "a universidade relevante passa a ser aquela que pode ser útil, flexível, empreendedora, operacional e inovadora, e que, além disso, desenvolve as competências requeridas pelo mercado de trabalho, assegurando, pelo menos em tese, maior empregabilidade" (Ferreira \& Oliveira, 2011, pp. 41-42, grifo dos autores).

Como se observa, evidenciam-se alguns fatores que têm comprometido a efetivação da gestão democrática da educação. $O$ desafio passa a ser, então, encontrar alternativas concretas para mudar tal situação. Diversos autores, amplamente citados ao longo deste artigo, indicam os pressupostos que podem nortear esta tarefa.

Para Chauí (2003) a autonomia universitária é um dos caminhos, mas esta só se efetivaria quando as universidades recuperassem o poder e a iniciativa de definição de suas próprias linhas de pesquisa e prioridades. Situação que, de acordo com a autora, somente se alterará quando a universidade pública for pensada pela perspectiva da formação e da democratização que, por sua vez, implica em condições que dizem respeito à educação como direito; à autonomia universitária (institucional, intelectual e financeira); à democratização da educação superior; à revalorização da docência; à revalorização da pesquisa; ao financiamento das pesquisas nas universidades públicas; e ainda, a uma visão crítica sobre o conceito de modernização que tem submetido as universidades públicas aos interesses do capital em detrimento dos direitos dos cidadãos.

Quanto à autonomia universitária, Fávero (2005) afirma que a construção efetiva deste princípio continua sendo um tema de luta de entidades, associações científicas e grupos organizados dentro e fora das universidades. Para ela, a consolidação da autonomia e da democracia na universidade apoia-se na ideia de que:

Uma instituição universitária apresenta sempre diversos graus de poder; [...] configurando o sistema como uma pirâmide [...]. Contudo, para que ela seja de fato democratizada, o poder deve fluir da base ao vértice, sem constituir-se um monopólio de nenhuma instância, mesmo dos que estão na administração superior. (Fávero, 2005, p. 79).

Fávero (2005) considera que a representação nos órgãos deliberativos e nos colegiados não representa a única forma de democratizar a universidade. Há que se criar espaço para uma participação efetiva no governo da instituição. A autora defende que a gestão democrática seja realizada em todos os níveis e instâncias das IES como reitoria, centros, faculdades, escolas, departamentos etc., seguindo-se de ações como transparência e visibilidade em todos os setores; ampliação de espaços para auscultação da comunidade acadêmica, de modo a Ihe proporcionar a participação no planejamento e nas deliberações tomadas pela instituição; bem como definição e explicitação desses espaços.

Ainda com respeito à autonomia universitária, Gutierrez e Catani (2008) veem nela a origem da participação dos diversos segmentos na administração das universidades públicas. Para esses autores, essa autonomia compreende as áreas didática, científica, administrativa e financeira. Entretanto, segundo Dal Ri, 1997 como citado em Gutierrez e Catani (2008), a própria comunidade universitária, na maioria das instituições públicas, não tem assegurado o controle sobre os mandatos dos dirigentes eleitos, assim como não se tem definida a política de gestão. Acrescente-se ainda o fato de que

Nas universidades públicas há um embate bastante dinâmico entre reitores, docentes, funcionários, alunos e suas respectivas entidades classistas, além de alguns segmentos organizados da sociedade, externos às instituições de ensino superior (Gutierrez \& Catani, 2008, pp. 67-68)

Para Santos e Carbonera (2010) a gestão exige um acentuado grau de autonomia que permita a criatividade e a inovação e que deve "estar associada à corresponsabilidade de compartilhar as decisões entre os diversos níveis e segmentos representativos da organização de educação de forma verdadeiramente democrática" (Santos \& Carbonera, 2010, p. 187).

Ferreira e Oliveira (2011) questionam se a universidade poderá resguardar sua capacidade de autodefinição e de reflexão crítica contrapondo-se ao imediatismo e ao pragmatismo que comandam a produção acadêmica e provocam um desequilíbrio entre a ênfase na pesquisa básica e na pesquisa aplicada e/ou tecnológica. Diante de tal situação, eles defendem, além da criação de redes nacionais e internacionais de cooperação e solidariedade, e do financiamento ou investimento público para as universidades públicas, a gestão democrática, pois consideram que:

O processo de redefinição das finalidades da universidade sem um
amplo debate democrático pode comprometer sua identidade
histórica bem como pode colocar em risco sua existência como
espaço de exercício do questionamento, do confronto de ideais e da
busca de alternativas para a existência da humanidade e para a
melhora da qualidade de vida do conjunto da sociedade. Os papéis
sociais a serem exercidos pelas universidades devem ser
permanentemente objeto de reflexão e estar articulados a um
projeto de sociedade democrática, voltada para os interesses e
direitos de todos seus cidadãos e não apenas para a satisfação de
determinados grupos sociais. (Ferreira \& Oliveira, 2011, p. 58).

A relevância da participação social é compartilhada por Peroni e Flores (2014) por entenderem que a gestão democrática na educação faz parte do projeto de construção da democratização da sociedade brasileira. Entretanto, essas autoras percebem uma atuação dual do Estado que interfere na definição das finalidades e das prioridades das instituições públicas de ensino. Diante da correlação de forças vigente, o Estado vive a tensão entre o seu compromisso com a oferta educacional pública de qualidade como garantia de direitos sociais e, por outro lado, a cobrança, por parte do mercado, da inclusão de práticas mercantilistas na política pública na área educacional.

Esse dualismo, segundo Peroni e Flores (2014), se apresenta na Meta 19 do PNE atual, cuja proposta de gestão democrática 
inclui critérios do modelo de gestão gerencialiii e, ao mesmo tempo, aponta de forma genérica a participação da comunidade escolar. No entendimento das autoras, o texto do PNE demonstra uma tentativa de articulação de "mecanismos de gestão que representam concepções diferentes e mesmo antagônicas de gestão, uma de matriz democrática e outra vinculada a modelos de viés gerencial, restando aos entes federados o desafio de implementar conjuntamente critérios tão distintos". (Peroni \& Flores, 2014, p. 186).

Percebe-se, a partir das contribuições destes diversos autores, que a educação superior não ficou imune aos ditames do capital e, por isto, tem sido motivo de embates políticos entre grupos que propõem para este campo caminhos diversos: um para a direção de sua mercantilização e outro para a sua distinção como bem público e, portanto, inegociável.

Para aqueles grupos que lutam pela via contra-hegemônica, este cenário complexo e contraditório é também repleto de possibilidades. E um dos caminhos propostos nesta batalha é a efetivação da democratização da gestão da educação, por meio da ampliação da participação social nos espaços decisórios institucionais.

\section{Participação social: espaços e atores}

A participação social em espaços e processos de discussão e formulação de políticas públicas, em uma sociedade democrática, é considerada como uma importante contribuição dos cidadãos e, ao mesmo tempo, motivo de constantes embates pelos espaços e formas de sua realização.

Bordenave (1994) define a participação social como macroparticipação ou participação macrossocial, isto é, aquela participação que compreende a "intervenção das pessoas nos processos dinâmicos que constituem ou modificam a sociedade, quer dizer, na história da sociedade" (Bordenave, 1994, p. 24). Neste sentido, a participação do cidadão ocorre no nível macro ao intervir nas lutas sociais, econômicas e políticas de seu tempo. Diferentemente, a microparticipação se dá no nível dos interesses pessoais e imediatos. Este autor busca o conceito de participação cunhado por Ammann (1982): "participação social é o processo mediante o qual as diversas camadas sociais têm parte na produção, na gestão e no usufruto dos bens de uma sociedade historicamente determinada" (Ammann, 1982 como citado em Bordenave, 1994, p. 25).

Embora se saiba que a história brasileira é muito rica em relação às manifestações sociais de descontentamento com as situações sociais, políticas e econômicas vivenciadas pela população desde que aqui chegaram os colonizadores, este artigo aborda o período recente em que o país viveu o regime opressor da ditadura até os dias atuais. Aquele pode ser considerado, historicamente, um período em que muitos brasileiros optaram por demonstrar publicamente sua insatisfação com a centralização do poder no país, ainda que sob o risco de morte. Estava em jogo, naquele momento, a busca pelo direito de influir nas políticas públicas que seriam implementadas no país.
Já na década de 1970, observa-se a presença de diversos protagonistas nos movimentos sociais pela redemocratização do país e pela consolidação e garantia de direitos "tais como os movimentos de trabalhadores urbanos e rurais, os movimentos populares, de mulheres, de homossexuais, étnicos, de meninos e meninas que vivem nas ruas, movimento pela cidadania e ética na política, movimentos ecológico e ambientalista" (Kauchakje, 2002, p. 163).

Mesmo com as mudanças ocorridas na gestão dos serviços da área social a partir do final da década de 1990iv, Gohn (2004) acredita que o diálogo e o exercício da vida política/cultural na esfera pública, contribuiriam para o desenvolvimento de uma nova cultura política no país, uma nova cultura ética com civilidade e respeito ao outro. Para ela, estava colocada uma nova forma de se democratizar a gestão da coisa pública, uma vez que essa nova cultura política se contraporia à tradição autoritária, às práticas clientelistas ou corporativas de grupos patrimonialistas, oligárquicos ou modernos/privatistas. Trata-se, portanto de "uma cultura política gerada por processos nos quais os diferentes interesses são reconhecidos, representados e negociados, via mediações sociopolíticas e culturais" (Gohn, 2004, p.28).

Luchmann (2006) indica a criação de diferentes espaços e níveis de participação política a partir da Constituição Federal de 1988 - CF/1998. Para além da ação do voto, a participação tem seu sentido ampliado, referindo-se também, a partir de então, à participação nos processos decisórios, com perspectiva ativa e deliberativa. Toma-se, para melhor compreensão sobre as formas existentes de participação social, algumas considerações desta autora a respeito dos dois modelos contemporâneos de democracia. A democracia direta que "diz respeito, de maneira geral, ao processo de discussão e deliberação política pautado nos princípios da igualdade, liberdade e cidadania plena, caracterizada pela participação direta dos cidadãos nos assuntos de Estado" (Luchmann, 2006, p. 20) e a democracia representativa, onde "a relação entre democracia e participação está ancorada em uma concepção de participação e de política que transfere o processo decisório para os representantes eleitos através do sufrágio eleitoral" (Luchmann, 2006, p. 21). Esta autora provavelmente se inspira em Bobbio para quem a democracia se refere a "um conjunto de regras (as chamadas regras do jogo) que consentem a mais ampla e segura participação da maior parte dos cidadãos, em forma direta ou indireta, nas decisões que interessam a toda a coletividade" (Bobbio, 1983, p. 55).

Este autor, porém, defende que a democracia direta, em uma sociedade cada vez mais complexa, só é realizável em grupos pequenos ou em assuntos que envolvam questões gerais que possam ser decididas a partir de respostas polarizadas como sim ou não. Para ele, o modo representativo da democracia apresenta a vantagem de simplificar a multiplicidade de opiniões. Ele afirma que não há incompatibilidade entre estas duas formas de democracia, mas assume que há um grande problema no sistema democrático representativo quando este não consegue atingir a representação efetiva de todos os cidadãos envolvidos ou que 
serão atingidos pelas consequências das decisões tomadas.

Luchmann $(2006,2012)$ também não omite que tais modelos sofreram críticas e que, a partir dos anos 1960, desenvolveu-se uma concepção participativa ou republicana de democracia, com ampla participação dos cidadãos em assuntos de interesse da coletividade. $E$ isto se deu, segundo a autora, com o intuito de recuperar a dimensão normativa da democracia, bem como de retomar a articulação entre os conceitos de cidadania e de soberania popular. Assim, ela apresenta as principais características da democracia participativa ou deliberativa, das quais se destacam: o resgate da soberania popular ou o reconhecimento de que cabe aos cidadãos a decisão sobre questões de interesse público; e o reconhecimento do pluralismo cultural, das desigualdades sociais e da complexidade social (Luchmann, 2006).

A autora lembra que, em nosso país, o processo de redemocratização ocorrido após 1985 resultou na emergência desta nova concepção acerca da democracia. A partir de então, cresceu a demanda por participação nos movimentos sociais, partidos políticos de esquerda e ainda setores acadêmicos e de várias entidades profissionais e representativas, que apostavam em uma efetiva partilha de poder entre Estado e sociedade civil na formulação e decisão sobre o interesse público. Neste contexto, várias experiências de gestão de políticas públicas de caráter participativo foram implementadas no Brasil, destacando-se, inicialmente, os Conselhos Gestores de Políticas Públicas (Saúde, Assistência Social, Criança e Adolescente e outros) e as experiências de Orçamento Participativo.

Nesta mesma direção de análise dos processos de participação popular, Gohn $(2013,2014)$ relata as mudanças nas orientações das ações coletivas e na forma de associativismo da sociedade civil organizada, ao longo das últimas décadas. Resulta daí o surgimento das redes sociais e temáticas, nas quais se organizam as atuais formas de associações civis, compostas por movimentos sociais, associações comunitárias, fóruns, conselhos, câmaras, assembleias, etc., e que podem ser agrupadas em três grandes blocos: movimentos e ações de grupos identitários; movimentos e organizações de luta por melhores condições de vida e de trabalho; e movimentos globais ou globalizantes.

Este novo milênio, depara-se, portanto, com novos atores sociais protagonistas das ações coletivas na sociedade civil, representados, conforme Kauchakje (2002), Gohn (2004, 2006, 2013, 2014) e Luchmann (2012) pelos sujeitos sociopolíticos: os movimentos sociais; as organizações não governamentais (ONGs); os fóruns, as plenárias e articulações nacionais e transnacionais; e os conselhos gestores de projetos, programas ou políticas sociais. Gohn (2014) identifica, neste novo século, a promoção da interação entre movimentos sociais, sindicatos e ações coletivas e órgãos governamentais e políticas de recuperação do salário dos trabalhadores. O governo de tendência socialista que assumiu na primeira metade da década de 2010 intensificou a implementação das políticas de inclusão ou de proteção social, voltadas para segmentos como os afrodescendentes e mulheres, bem como para o tema da alimentação. A forma com que se propunha a participação dos cidadãos nas políticas públicas propiciou a territorialização das ações coletivas e a tematização dos conflitos sociopolíticos. Acrescenta-se a esse cenário a existência do grande número de redes civis de atuação direta junto à população por meio de ONGs, associações comunitárias, sociedades de amigos de bairros, entidades assistenciais e filantrópicas, laboratórios de projetos sociais de extensão universitários, entre outros.

Estas redes de mobilização e participação da sociedade civil no país foram consideradas por Gohn $(2013,2014)$ como agentes estruturantes de energias sociais e fontes de inovações que atuam como elo para as articulações políticas e culturais entre os movimentos sociais, promovendo novas formas de organização como os fóruns específicos, transversais ou transnacionais.

A autora ressalta que os novos ordenamentos constitucionais para as políticas públicas e sociais, criados no final do século passado, promoveram mudanças que enfatizaram a responsabilização dos cidadãos, das empresas e dos órgãos governamentais e criaram espaços para a participação social nessas políticas, mediante parcerias, ou nos espaços criados institucionalmente (Gohn, 2014).

O novo século apresentou-nos mudanças nas políticas sociais,
desconcentração de várias atividades estatais na área social,
aplicação das novas legislações no âmbito federal com a criação de
organizações sociais (OSs), organizações da sociedade civil de
interesse público (Oscip's) e programas em parceria público-privado
(PPP), entre outras alterações de ordem institucional. [...] Novas
redes de participação institucionalizadas foram criadas com
conselhos, câmaras, fóruns e assembleias nacionais,
implementadas pelo poder público via políticas sociais para atender
novas exigências constitucionais. (Gohn, 2014, p. 80).

Estas novas arenas de intermediação e novos mecanismos decisórios, que incorporam uma grande pluralidade de atores e de diferentes interesses, representam a instauração de um novo padrão de interação entre governo e sociedade civil para o direcionamento das políticas públicas e sociais (Gohn, 2006). Há, portanto, segundo esta autora, novidades nas demandas, nas identidades, nos repertórios e no perfil dos participantes. Muitos dos grupos de mobilização social atuais são formados predominantemente por jovens, em sua maioria sem trajetória anterior de participação política em partidos e sindicatos. E, quanto às novas formas de luta ou protestos, as marchas e as ocupações tornaram-se o modelo básico, retomado na segunda década do século XXI, agora, aliado a outras inovações como o uso das novas tecnologias, especialmente as redes digitais e redes sociais (Gohn, 2014).

Santos e Avritzer (2009) também advogam que o processo de democratização pelo qual passou o Brasil apresenta "a possibilidade da inovação entendida como participação ampliada de atores sociais de diversos tipos em processo de tomada de decisão" (Santos \& Avritzer, 2009, p. 59), com inclusão de novas temáticas, redefinição de identidades e de vínculos e ainda o aumento da participação, principalmente no nível local.

Segundo eles, aquela concepção hegemônica de democracia representativa era defendida por Bobbio e outros autores devido ao 
receio da sobrecarga democrática promovida pelo excesso de opiniões e de demandas. Com este argumento, o processo de intensificação democrática foi combatido pelas elites e descaracterizado por cooptação de grupos reivindicatórios ou pela sua integração nos contextos institucionais e até mesmo pelo desencorajamento. O que retirou o seu "potencial democrático e de transformação das relações de poder" (Santos \& Avritzer, 2009, p. $60)$ e demonstrou a fragilidade e vulnerabilidade da participação.

Santos e Avritzer (2009) afirmam também que com o aumento do número dos atores envolvidos na política, da diversidade étnica e cultural e dos interesses envolvidos em arranjos políticos, os grupos mais vulneráveis, menos favorecidos e as etnias minoritárias não têm seus interesses representados da mesma forma que os outros grupos.

Em tom de crítica à teoria hegemônica da democracia representativa, eles afirmam a existência de duas formas de combinação entre democracia participativa e democracia representativa: a) a coexistência da democracia representativa em nível nacional com a democracia participativa em nível local; b) a complementaridade que implica uma articulação profunda entre democracia representativa e democracia participativa, com o reconhecimento de que "o procedimento participativo, as formas públicas de monitoramento dos governos e os processos de deliberação pública podem substituir parte do processo de representação e deliberação tais como concebidos no modelo hegemônico de democracia" (Santos \& Avritzer, 2009, p. 76).

Como defensores da democracia participativa, estes autores apresentam três teses para o seu fortalecimento. São elas: a demodiversidade (complementaridade entre várias formas de democracia); a articulação contra-hegemônica entre o local e o global; e a ampliação do experimentalismo democrático (abrir espaço para novas formas de participação).

O que se depreende, portanto, é que as condições para a realização das várias formas de participação democrática têm seus fundamentos normatizados em nosso país desde a CF/1988, mas não foram regulamentados devido aos interesses contrários a um projeto societário emancipatório e transformador. Um bom exemplo disto foi a não aprovação, pelos parlamentares, do Decreto $\mathrm{n}$ ㅇ. 8.243 (2014) que instituiria a Política Nacional de Participação Social (PNPS) e o Sistema Nacional de Participação Social (SNPS). O objetivo de tal lei seria o de "fortalecer e articular os mecanismos e as instâncias democráticas de diálogo e a atuação conjunta entre a administração pública federal e a sociedade civil" (Decreto $n$. 8.243, 2014, art. $\left.1^{\circ}\right)$. Esta iniciativa buscava garantir a participação social na formulação, execução, monitoramento e avaliação de programas e políticas públicas e, consequentemente, no aprimoramento da gestão pública.

Resta, então, que se continuem os embates e que se persiga a efetivação da democracia participativa como uma das formas de defesa dos interesses sociais nas instâncias definidoras das políticas públicas, sociais e econômicas que vêm sofrendo com a interferência hegemônica do capital.

\section{Participação social nas universidades públicas federais}

A complexidade do novo contexto político institucional, a partir da década de 1980, requer do Estado a renovação de sua ação, de maneira que acompanhe as transformações ocorridas na organização da sociedade que se tornou diversa, democrática e que luta por seus direitos. E isto ocorre também na área da educação, onde se percebe uma multiplicação de instâncias e momentos de decisão, uma diversificação de formas de associação no interior dos espaços públicos e um envolvimento de maior número de atores (Barroso, 2005).

A regulamentação da democratização da educação em 1996 representa a materialização dos anseios destes atores sociais e, ao mesmo tempo, traz desafios para as instituições em todos os níveis de ensino (municipal, estadual e federal), pois contém em suas entrelinhas a necessidade de estas se organizarem, a fim de garantir a participação política de todas as pessoas envolvidas nos processos escolares.

Importante considerar também toda a discussão realizada nos itens anteriores sobre a gestão democrática da educação no Brasil, e os entraves que o contexto político e econômico trouxe para sua efetivação, bem como sobre a participação social, seus sujeitos e instâncias de realização. Mas nunca é demais refletir sobre os fundamentos para a implementação da gestão democrática das escolas e da Política de Educação no país e como isto se traduz em nova forma de gestão das instituições públicas de ensino superior, especificamente das universidades públicas federais.

Melo (2010) relaciona a democracia participativa na escola à "participação efetiva de todos os envolvidos e interessados nas deliberações da escola: professores, diretores, equipe pedagógica, funcionários, pais e alunos". (Melo, 2010, p. 1, - grifo da autora).

Esta autora afirma que há diferentes formas, sentidos e significados que podem ser atribuídos ao ideal de participação. Para alguns autores, a transferência de autoridade e de responsabilidade pela gestão de um bem público para um grupo diretamente envolvido no trabalho representa uma prática democrática e socialmente justa. Outros, entretanto, denunciam a retórica da participação em que participar consiste em aplicação e fiscalização das deliberações realizadas de forma centralizada pelo governo ou por determinado setor da sociedade.

A área da educação é, historicamente, segundo Gohn (2008, 2013),

Fonte de demandas e reivindicações de todos os segmentos sociais que compõem o seu universo, professores e demais profissionais do ensino, estudantes, pais ou responsáveis, gestores e proprietários de estabelecimentos de ensino etc." (Gohn, 2013, p. 58).

Por conseguinte, as instituições públicas de ensino superior apresentam em seu âmbito a emergência de movimentos sociais pela educação que lutam por questões de conteúdo escolar, bem como por direitos relacionados a gênero, etnia, nacionalidade, religiões, necessidades especiais educacionais, meio ambiente, além de outros. Entre as recentes fontes de demandas e mobilizações percebidas na educação formal, essa autora elenca determinados temas como escola pública de qualidade, gestão 
democrática da escola, redefinição do conceito de participação, luta dos professores e outros profissionais da educação por condições salariais e de trabalho, luta dos estudantes por redução de tarifas de restaurantes universitários.

Carvalho (2013), que realizou estudo sobre o processo de gestão da universidade pública federal brasileira, aponta que a participação da comunidade universitária:

Nesse início de século XXI, constitui-se uma problemática de múltiplas determinações endógenas e exógenas. Tais determinações condicionam as políticas públicas educacionais e afetam a participação dos membros da comunidade universitária. (Carvalho, 2013, p. 352).

Segundo este autor, especialmente nas Instituições Federais de Ensino Superior (IFES), o tema da participação é assunto que preocupa a comunidade universitária (docentes, discentes e técnico-administrativos em educação), tendo, porém, sentidos diferentes para gestores, entidades representativas, cientistas e até mesmo estudiosos da área, conforme os interesses envolvidos. $O$ processo de mercantilização da educação superior não abre espaço à participação democrático-participativa, antes permitindo apenas a participação liberal representativa (Carvalho, 2013).

O autor afirma que o "entendimento da participação na universidade pública, principalmente nas IFES, passa pela compreensão da forma como o poder historicamente tem-se estruturado no seu interior e como a autonomia e a democratização aí se constituíram" (Carvalho, 2013, p. 355). Ele ressalta que forças político-sociais, extrínseca e intrinsecamente mobilizadas, têm impactado a organização da universidade. Externamente, a pressão se dá pelos organismos multilaterais, a sociedade em geral e até mesmo pelos governos, que dificultam o seu processo de autonomia. Internamente, há a disputa por formas diferenciadas de gestão que comportem a verticalização ou a horizontalização do poder decisório.

Carvalho afirma que a dinâmica neoliberal imposta na área da educação tem escamoteado a dimensão política em aspectos de natureza técnica, ou seja, as questões de ordem político-sociais são transformadas em questões de natureza técnico-instrumentais. Consequentemente, gera-se um discurso que dá à participação o sentido do "agir individual na definição dos objetivos e métodos educacionais operacionais, transmitindo a sensação de democracia, escolha e participação" (Carvalho, 2013, p. 356). Nesta perspectiva de gestão gerencial de natureza estratégicoempresarial adotada pelo governo brasileiro na década de 1990 (e vigente na atualidade), a participação nas instituições públicas se reduz ao compartilhamento da informação e à conscientização dos servidores sobre a missão institucional e sobre os resultados globais desejados. Como resultado, observa-se a segmentação entre um pequeno grupo de envolvidos nos processos de tomada de decisão e o restante dos sujeitos convocados à execução daquilo que fora planejado anteriormente, seja pelo grupo detentor do poder de decisão no âmbito da instituição ou pela burocracia estatal externa.

A preocupação das IFES, desde o advento da reforma do Estado e da educação, tem sido o fantasma do controle por meio dos contratos de gestão e a pressão pela adequação à lógica mercadológica de organizações sociais (Carvalho, 2013). Além do que, no interior desta universidade que se torna operacional, a prática educativa é "cada vez mais pragmática e utilitarista em contraste com uma perspectiva mais emancipatória, autônoma e democrática" (Carvalho, 2013, p. 358). Outros fatores que têm arrefecido a participação na vida institucional e possibilitado a centralização do processo de tomada de decisão em órgãos administrativos, segundo este autor, são o individualismo e a competição por recursos extraorçamentários. Entretanto, mesmo nesta realidade contraditória de ambiente estatal impregnado pela lógica econômica-mercantilista, este autor identifica sinais de resistência acadêmica, sindical e trabalhista, a qual tem potencial de revigoramento da dimensão política nas IFES. Segundo ele, o ambiente institucional destas instituições, muitas vezes considerado pouco participativo, comporta disputas entre os segmentos da comunidade universitária por maior participação, tanto em espaços formais quanto não formais de tomadas de decisão. Já no âmbito nacional, a luta por democratização e maior participação na gestão universitária tem como protagonistas as entidades representativas dos docentes, discentes e trabalhadores das instituições de ensino superior.

Estas instituições vêm sofrendo com a conjuntura econômica mundial que também assola o país. Neste último ano, por exemplo, os ajustes no orçamento nacional implicaram em corte de verbas para a educação, inviabilizando o pleno funcionamento de várias IFES. Com quadro já reduzido de funcionários e docentes, elas passam a enfrentar problemas de infraestrutura, dificuldade para pagamento dos contratos com terceirizados, das contas de manutenção como água, energia e compra de suprimentos básicos, bem como do atendimento à assistência estudantil para o crescente número de estudantes que nos últimos anos acessaram o ensino superior público por meio do REUNI, das ações afirmativas e da Lei no 12.711/2012 (lei de cotas ou de reserva de vagas).

Tal situação vivenciada pelas universidades públicas no Brasil é produto de vários fatores além daqueles já mencionados neste texto. Há vários autores debruçados sobre respostas para uma mudança substantiva para a questão. Dentre eles, está Santos (2011) que propõe uma reforma criativa, democrática e emancipatória da universidade pública. Entre outros elementos necessários para alcançar tal intento, ele apresenta a

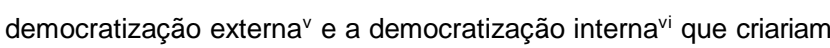
um vínculo político orgânico entre a universidade e a sociedade, pondo fim ao isolamento desta instituição. Atendendo ao apelo das forças sociais progressistas que provêm de grupos historicamente excluídos, a universidade precisaria assumir o modelo pluriversitário, que implica na contextualização do conhecimento, e a participação dos cidadãos ou comunidades como utilizadores e coprodutores desse conhecimento.

Segundo Santos (2011), a democracia externa, aliada à interna, teria o potencial de neutralizar o avanço da privatização das universidades, conclamado pelo mercado educacional. Este teve enorme impacto nestas instituições, inclusive sobre o controle das 
agendas de pesquisa, priorizando aquelas que são mais lucrativas e limitando as ações aos interesses do mercado em detrimento das questões sociais.

Portanto, uma relação transparente entre a universidade e a sociedade, com legitimação das decisões tomadas no âmbito institucional, pode se tornar um elo de forças para o enfrentamento das pressões neoliberais.

\section{Considerações finais}

O contexto sócio-histórico de hegemonia neoliberal com suas determinações de ordem econômica e política tem imprimido, desde a última década do século anterior, uma lógica gerencial na gestão pública do Brasil, inclusive na área da educação.

As reformas do Estado e da educação alteraram profundamente a oferta da educação em todos os níveis de ensino, bem como a sua própria essência como direito público e social. Em um movimento ambíguo, o Estado abre espaço para a gestão empresarial na educação, ao mesmo tempo em que determina a democratização de sua gestão. Porém, mesmo nas instituições públicas estatais, a mercadorização da educação tem implicado na utilização de práticas de competitividade e exclusão. E isto, certamente entra em conflito com os princípios de equidade, solidariedade e inclusão que fundamentam a educação como bem público e direito social (Dias Sobrinho, 2013).

A efetivação da democratização da educação sob estas condições requer um esforço de se compreender as formas de democracia existentes na sociedade e como estas se concretizam. A escola e as instâncias de planejamento da Política de Educação estão sujeitas a esta tomada de decisão, seja ela de cunho mais participativo ou apenas representativo. Quanto à participação social nas universidades públicas federais, verifica-se a necessidade de alteração da situação vigente em muitas instituições, pois a verticalização e segmentação do poder é uma realidade que não atende aos mínimos critérios democráticos de representatividade, quiçá da representação dos grupos historicamente excluídos dos processos de decisão e também da socialização das riquezas produzidas.

\section{Referências}

Amaral, N. C. (2011). O financiamento da expansão das instituições federais de ensino superior no contexto de um novo Plano Nacional de Educação 2011-2021. In: J. F. de Oliveira (Org.) O Campo universitário no Brasil: políticas, ações e processos de reconfiguração (pp. 63-86), Campinas, SP: Mercado das Letras.

Barroso, J. (2005). O Estado, a educação e a regulação das políticas públicas. Revista Educação e Sociedade, 26 (92), pp. 725-751. Recuperado de http://www.scielo.br/pdf/\%0D/es/v26n92/v26n92a02.pdf

Bordenave, J. E. D. (1994). O que é participação (8a ed.). São Paulo: Brasiliense.

Bobbio, N. (1983). Qual socialismo?: debate sobre uma alternativa (Freaza, I. S. trad.). Rio de Janeiro: Paz e Terra. Constituição da República Federativa do Brasil de 1988 (1988). Diário Oficial da União. Brasília, DF: Senado Federal.

Decreto $n^{\circ}$ 8.243, de 23 de maio de 2014. (2014). Institui a Política Nacional de Participação Social e o Sistema Nacional de Participação Social e dá outras providências. Diário Oficial da União. Brasília, DF: Presidência da República.

Carvalho, R. F. de (2013). Limites, possibilidades e desafios no processo de gestão e participação das IFES/UFT. Avaliação (Campinas; Sorocaba), 18(2), pp. 351-372. Recuperado de http://periodicos.uniso.br/ojs/index.php?journal=avaliacao\&page=article\&op= view\&path\%5B\%5D=1585\&path\%5B\%5D=pdf

Chauí, M. (2003). A universidade pública sob nova perspectiva. Revista Brasileira de Educação, (24), pp. 5-15. Recuperado de http://www.scielo.br/pdf/rbedu/n24/n24a02.pdf

Dias Sobrinho, J. (2013). Educação superior: bem público, equidade e democratização. Avaliação (Campinas; Sorocaba), 18 (1), pp. 107-126. Recuperado de http://www.scielo.br/pdf/aval/v18n1/07.pdf

Dourado, L.F. (2007). Políticas e gestão da educação básica no Brasil: limites e perspectivas. Educação \&. Sociedade 28(100), pp. 921-946. Recuperado de http://www.scielo.br/pdf/es/v28n100/a1428100.pdf

Dourado, L.F. (2010). Avaliação do plano nacional de educação 2001-2009: questões estruturais e conjunturais de uma política. Educação \&. Sociedade, 31(112), 677-705. Recuperado de http://www.scielo.br/pdf/es/v31n112/03.pdf

Dourado, L.F. (2011). Políticas e gestão da educação superior no Brasil: múltiplas regulações e controle. RBPAE, 27(1), pp. 53-65. Recuperado de http://seer.ufrgs.br/index.php/rbpae/article/view/19967/11598

Dourado, L.F. (2013). Políticas de educação superior: avanços e desafios. In: P. Gentili (Org.). Política educacional, cidadania e conquistas democráticas (pp. 59-65). São Paulo: Editora Fundação Perseu Abramo.

Dourado, L.F., Catani, A. M., \& Oliveira, J. F. de. (2004). Políticas públicas e reforma da educação superior no Brasil: impasses e perspectivas. ProPosições, 15(3), pp. 91-115. Recuperado de http://www.proposicoes.fe.unicamp.br/proposicoes/textos/45-dossiedouradolf_etal.pdf

Fávero, M.L. A. (2005). Autonomia e democratização da Universidade. Avaliação - Revista da Rede de Avaliação Institucional da Educação Superior, 10(4), pp.75-86. Recuperado de http://periodicos.uniso.br/ojs/index.php?journal=avaliacao \&page=article\&op= view\&path\%5B\%5D=1326\&path\%5B\%5D=1316

Ferreira, S., \& Oliveira, J. F. de. (2011). As influências da reforma da educação superior no Brasil e na União Europeia nos papéis sociais das universidades. In: J. F. de Oliveira (Org.) O Campo universitário no Brasil: políticas, ações e processos de reconfiguração (pp.39-62). Campinas, SP: Mercado das Letras.

Gonh, M. G. M. (2004). Empoderamento e participação da comunidade em políticas sociais. Saúde e Sociedade, 13(2), pp. 20-31. Recuperado de http://www.scielo.br/pdf/sausoc/v13n2/03.pdf

Gohn, M. G. M. (2006). Conselhos gestores e gestão pública. Ciências Sociais Unisinos, 42(1), 5-11. Recuperado de http://revistas.unisinos.br/index.php/ciencias_sociais/article/view/6008

Gohn, M. G. M. (2008). História dos movimentos e lutas sociais: a construção da cidadania dos brasileiros (4a ed.). São Paulo: Edições Loyola.

Gohn, M. G. M. (2013). Movimentos sociais e redes de mobilizações civis no Brasil contemporâneo (5a ed.). Petrópolis, RJ: Vozes.

Gohn, M. G. M. (2014). Pluralidade da representação na América Latina. Revista Sociedade e Estado, 29(1), pp. 73-90. Recuperado de http://www.scielo.br/pdf/se/v29n1/05.pdf

Gutiérrez, G. L., \& Catani, A. M. (2008). Participação e gestão escolar: conceitos e potencialidades. In N. S. C. Ferreira (Org.). Gestão democrática da educação: atuais tendências, novos desafios (pp. 59-75). São Paulo: Cortez.

Kauchakje, S. (2002). Participação social no Brasil diante da desestruturação das políticas sociais: novas configurações da sociedade civil organizada como alternativa para recompor os laços sociais e a civilidade nas relações societárias. Emancipação, 2(1), pp. 159-176). Recuperado de http://www.revistas2.uepg.br/index.php/emancipacao/article/view/35/32

Lei $n^{\circ}$ 9.394, de 20 de dezembro de 1996. (1996). Estabelece as diretrizes e bases da educação nacional. Diário Oficial da União. Brasília, DF: Senado Federal.

Lei no 13.005, de 25 junho de 2014. (2014). Aprova o Plano Nacional de Educação - PNE e dá outras providências. Diário Oficial da União. Brasília, DF: Senado Federal.

Lüchmann, L. H. H. (2006). Os sentidos e desafios da participação. Ciências Sociais Unisinos, 42(1), pp. 19-26. Recuperado de http://revistas.unisinos.br/index.php/ciencias_sociais/article/view/6011

Lüchmann, L. H. H. (2012). Participação e aprendizado político no orçamento participativo: estudo de caso em um município catarinense. Educação \& Sociedade, 33(119), pp. 513-532. Recuperado de

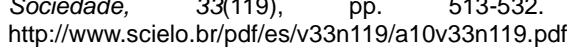

Maia, M. Z. B. (2011). Políticas públicas para a educação superior no Brasil a partir dos anos 1990: o papel da educação à distância. In: J. F de Oliveira (Org.) O Campo universitário no Brasil: políticas, ações e processos de reconfiguração (pp.87-108). Campinas, SP: Mercado das Letras.

Melo, L.F. Democracia participativa na escola. In: Oliveira, D.A., Duarte, 
A.M.C.\& Vieira, L.M.F. DICIONÁRIO: trabalho, profissão e condição docente. Belo Horizonte: UFMG/Faculdade de Educação, 2010. [CD-ROM]

Mendonça, E. F. (2001). Estado patrimonial e gestão democrática do ensino público no Brasil. Educação \& Sociedade, 22(75), pp. 84-108. Recuperado de http://www.scielo.br/pdf/es/v22n75/22n75a07.pdf

Oliveira, J. F. de \& Catani, A. M. (2011). A reconfiguração do campo universitário no Brasil: conceitos, atores, estratégias e ações. In: J. F. de Oliveira (Org.) O Campo universitário no Brasil: políticas, ações e processos de reconfiguração (pp.11-38). Campinas, SP: Mercado das Letras.

Peroni, V. M.V. (2012) A gestão democrática da educação em tempos de parceria entre o público e o privado. Pro-Posições, 23(2), pp. 19-31. Recuperado de http://www.scielo.br/pdf/pp/v23n2/a03v23n2.pdf

Peroni, V. M. V., \& Flores, M. L. R. (2014). Sistema nacional, plano nacional e gestão democrática da educação no Brasil: articulações e tensões. Educação, 37(2), pp. 180-189. Recuperado de http://revistaseletronicas.pucrs.br/ojs/index.php/faced/article/view/16342/117 37

Santos, A. P. dos, \& Carbonera, V. (2010). Gestão democrática da educação e avaliação em larga escala: implicações para o contexto escolar. Poiésis, $3(6)$ 177-192. Recuperado de http://www.portaldeperiodicos.unisul.br/index.php/Poiesis/article/view/544/53

i Banco Mundial (BM), Organização das Ações Unidas para a Educação (Unesco), Organização para Cooperação e Desenvolvimento Econômico (OCDE), entre outros.

ii A Declaração de Bolonha, assinada por 29 países europeus em 19 de junho de 1999 foi o marco fundamental de uma nova dinâmica imposta ao ensino superior da Europa com o objetivo de torna-la mais competitiva no mercado global.
3

Santos, B. S. (2011). A universidade do Século XXI: para uma reforma democrática e emancipatória da universidade (3a ed.). São Paulo: Cortez.

Santos, B.S., \& Avritzer, L. (2009). Para ampliar o Cânone democrático. In: B. S. Santos (Org.). Democratizar a democracia: os caminhos da democracia participativa (4a ed., pp. 39-82). Rio de Janeiro: Civilização Brasileira.

Sguissard, V. (2005). Universidade pública estatal: entre o público e o privado/mercantil. Educação \& Sociedade, 26(90), pp. 191-222. Recuperado de http://www.scielo.br/pdf/es/v26n90/a09v2690.pdf

Sguissard, V. (2008). Modelo de expansão da educação superior no Brasil: predomínio privado/mercantil e desafios para a regulação e a formação universitária. Educação \& Sociedade. 29(105), pp. 991-1022. Recuperado de http://www.scielo.br/pdf/es/v29n105/v29n105a04.pdf

Sguissard, V. (2013). Regulação estatal e desafios da expansão mercantil da educação superior. Educação \& Sociedade, 34(124), pp. 943-960. Recuperado de http://www.scielo.br/pdf/es/v34n124/15.pdf

Souza, D. B., \& Castro, D. F. (2012). Gestão democrática da educação sob perspectiva comparada Brasil-Portugal: entre a exigência legal e a exequibilidade real. Educação \& Sociedade, 33(121), pp. 1195-1213. Recuperado de http://www.scielo.br/pdf/es/v33n121/a15v33n121.pdf

iii Princípios gerenciais como os critérios técnicos de mérito e de desempenho.

iv Novo modelo de gestão pública implementado com a Reforma do Estado. v Com a criação de Conselhos Sociais que levem em conta a diversidade social e cultural da população.

vi Com a participação de grupos historicamente excluídos em grupos de decisão. 